http://jmscr.igmpublication.org/home/

ISSN (e)-2347-176x ISSN (p) 2455-0450

crossref DOI: https://dx.doi.org/10.18535/jmscr/v9i3.08

Journal Of Medical Science And Clinical Research

\title{
Sociodemographic and characteristics of mentally ill patients admitted in State Mental Health Hospital: A cross sectional study
}

\author{
Authors \\ Abhilaksh Kango ${ }^{1}$, Anukriti Singh ${ }^{2}$ \\ ${ }^{1}$ Psychiatrist, Himachal Hospital of Mental Health and Rehabilitation, Shimla (HP) \\ ${ }^{2}$ Medical officer, IGMC, Shimla (HP) \\ *Corresponding Author \\ Dr Abhilaksh Kango
}

Psychiatrist, Himachal Hospital of Mental Health and Rehabilitation, Shimla (HP), 171005

\begin{abstract}
Aim: To study the sociodemographic and clinical characteristics of patients admitted in $H H M H \& R$, Shimla.

Material and Methods: A cross-sectional study was done and patients admitted in both male and female psychiatry ward were included in study. Information regarding sociodemographic characteristics, clinical profile along with type of admission and availability of caregiver was collected.

Results: Majority of patients were male in their late 30s. Most common diagnosis was schizophrenia followed by psychosis unspecified. Majority of patients were destitute and admitted via reception orders from court. Most common prescribed drug was Olanzapine followed via haloperidol.

Conclusion: Destitute mentally ill patients makes an exclusive patient group with different presentations and unique challenges in management and reintegration with society. Actions to take care of this unique patients of the society and requirements to look after their proper application should be in place.

Keywords: Himachal Hospital of Mental Health and Rehabilitation (HHMH\&R), Reception order (RO), Hospital for Mental Health (HMH), Mental Health Care Act (MHCA).
\end{abstract}

\section{Introduction}

Around $2-5 \%$ of population in India is known to be affected from mental or behavioural issues. Out of which $1 \%$ has one or other severe mental disorder requiring inpatient care ${ }^{1,2}$. Destitution is an upcoming and grave issue among patients with severe mental illness with around $15 \%$ o f total patients $^{3-5}$. Around 400,000 nomadic mentally ill patients are there in our country ${ }^{3}$. They often face mental distress and physical abuse; mostly noticed around public spaces mostly around urban areas. Nine out of ten destitute have diagnosable and treatable mental disorders and co-morbidities are seen in four out of five patients ${ }^{3,6}$.

In our country there is not even one psychiatrist in $80 \%$ of districts ${ }^{2}$. So in current situation India will see a lot of destitute nomadic persons with mental illness ${ }^{2}$. This study is mainly emphasising on patients who were in general psychiatry ward at $\mathrm{HHMH} \& \mathrm{R}$, Shimla. There were 46 patients admitted at the time of observation. Hospital has a dedicated Clinical Psychologist but referral to other specialties is tough because only one psychiatrist and MBBS doctors are posted there. 
Patients with co-morbidities are referred to adjoining tertiary care centre ten kilometres away. Patients admitted here are mostly suffering from chronic mental illness and require long term inpatient stay. In nearby hospital other specialities are present where referral can be made and required investigations can be done. There mainly acutely disturbed patients are kept and patients in need of chronic care or destitute are referred to HHMH \& R, Shimla. The aim of the study is to analyse the socio-demographic, clinical profile in admitted patients at $\mathrm{HHMH} \& \mathrm{R}$, Shimla.

\section{Material and Methods}

A cross-sectional study was conducted in January 2021 in HHMH \& R Shimla after obtaining permission from authorities. Patients admitted in hospital were included in study irrespective of age and gender. Diagnosis was noted from records and MINI-PLUS was applied to confirm same. Sociodemographic data was obtained from records available in institution.

\section{Statistical Analysis}

Data was analysed using SPSS software in which descriptive statistics were used in form of mean, standard deviation was used for continuous variables and frequencies were used for categorical variables.

Table 1: Socio-demographic profile of patients

\begin{tabular}{|l|c|}
\hline Variables & $\begin{array}{c}\text { Patients } \\
\text { N=47 } \\
\text { Mean (SD)/ } \\
\text { Frequency (\%) }\end{array}$ \\
\hline Age in years & $37.28(11)$ \\
\hline Gender & $34(73.9 \%)$ \\
Male & $12(26.1 \%)$ \\
Female & $35(76.1 \%)$ \\
\hline Marital status & $11(23.9 \%)$ \\
Single & $36(78.3 \%)$ \\
Married & $10(21.7 \%)$ \\
\hline Type of admission & $26(56.5 \%)$ \\
Via reception order & $20(43.5 \%)$ \\
Voluntary/independent & \\
\hline Patient & $25(54.3 \%)$ \\
Destitute & $21(45.7 \%)$ \\
\hline Caregiver available/ traceable & \\
\hline Locality & Himachal Pradesh \\
Out of Himachal Pradesh &
\end{tabular}

Table 2: Clinical profile of patients

\begin{tabular}{|l|c|}
\hline Variables & $\begin{array}{c}\text { Patients } \\
\text { N=47 } \\
\text { Mean (SD)/ } \\
\text { Frequency (\%) }\end{array}$ \\
\hline Diagnosis & $16(34.8 \%)$ \\
Schizophrenia \\
Psychosis unspecified & $12(26.1 \%)$ \\
Others & $18(39.1 \%)$ \\
\hline Medication & $17(37.0 \%)$ \\
Olanzapine & $12(21.7 \%)$ \\
Haloperidol & $17(37.0 \%)$ \\
Others & $15(32.6 \%)$ \\
\hline Co-morbidity & $31(67.4 \%)$ \\
Yes & $23(50 \%)$ \\
No & $23(50 \%)$ \\
\hline Substance use history & \\
Yes & No \\
\hline
\end{tabular}

\section{Results}

Majority of patients were male, mean age was 37.28 years and majority were single $(76.1 \%)$. Most common diagnosis was schizophrenia followed by psychosis unspecified. Majority of patients $(56.5 \%)$ were destitute with no caregiver available or traceable. Mode of admission was through reception orders from court in majority of patients (78.3\%) rest of patients were admitted as independent or voluntary patients. Most patients (54.3\%) were from Himachal Pradesh and rest were from outside Himachal Pradesh. Most common prescribed drug was Olanzapine followed by Haloperidol. Around half patients had history of substance use in which most common was tobacco in various forms. In co-morbidities most common was hypertension (15\%) followed by diabetes mellitus $(8.7 \%) .\{$ Table $1 \&$ Table 2$\}$

\section{Discussion}

As observed in this and prior such studies nomadic patients with psychiatric illness make a peculiar patient group because they recurrently face physical/sexual abuse; they need assistance to bring them to health facility and due to linguistic barriers, majority of negative symptoms, cognitive deterioration and tendency to abscond they require constant supervision. Poorly treated mental illness was the utmost reason for nomadic patients ${ }^{7}$. One study completed in India (Goa) in patients 
admitted on basis of reception orders equated with those who got admitted on voluntarily basis, former were more commonly single, of middle age (in fourth \& fifth decade); and had a significant lengthier hospital stay than latter group. Psychotic illness without affective causation and substance abuse were the most commonly encountered diagnoses ${ }^{8}$. Koegel et al., did a similar study in Los Angeles in which major mental disorders were significantly higher in destitute group. Substance abuse was seen more in elder individuals and in subjects between 31 to 40 years schizophrenia was most prevalentdiagnosis ${ }^{9}$. Similar findings in form of more middle-aged, unmarried males were admitted by reception orders as compared to voluntarily admitted patients, male admissions were noted to be on higher side and involuntary admission reported to significantly involve young, single patients as well as middle-aged men in our study.

In our country, where family is responsible for patient care in community, being single may add on to difficulties in managing patients. Many times, mentally ill patients are found wandering away from home and even found away from native state. Due to their abnormal behavior, debilitated condition these individuals are picked up by the police under the provisions of the MHCA, due to which significant proportion of patients were from out of state which further lead to difficulty in management due to language difficulties and hampering rehabilitation of patients.

As apparent in above findings their fundamental actions should be taken and implementation should be monitored regularly to take care of this susceptible population. In current MHCA there is strong emphasis on not initialization of patients and to give proper chance for community participation which is not achievable without taking care of this group. State Hospitals for Mental Health can work in more efficient manner if experts from other medical fields visit frequently and dedicated staff for rehabilitation in form of psychiatric social worker, occupational therapist should be in place and co-ordination with NGOs who work in these areas should be done. And lastly psychiatry units in tertiary care centers should be strengthened as they play a major part in taking care of such patients.

\section{Conclusion}

Destitute patients with mental illness in our country is an evolving problem which requires instant interventions. Language difficulties is a main restrictive factor in managing of such patients. They frequently face physical, sexual abuse and other adversities. They suffer mostly from resistant illness due to poor treatment, with predominant negative symptom profile and cognitive deterioration which make outcome poor. Their management requires cooperation among various specialties in hospitals, other government bodies and NGOs. Above all strong policy making and infrastructure is necessary. Many of these patients can be reintegrated into society leading to a meaningful life if efforts are done in right directions.

\section{References}

1. Saraceno B, et al. Atlas: Mental Health Resources in the World, WHO. 2005.

2. Ahuja N. A Short Textbook of Psychiatry 7th edition. Chapter 21-Community Psychiatry. Jaypee Brothers Medical Publishers Private Limited. New Delhi (2011).

3. Politzer M \& Krishnan V. Mentally-ill-inindia-struggle-with-homelessnes.

(24/05/2012).

4. Folsom DP, Hawthorne W, Lindamer L, Gilmer T, Bailey A, Golshan S, et al. Prevalence and risk factors for homelessness and utilization of mental health services among 10,340 patients with serious mental illness in a large public mental health system. American Journal of Psychiatry. 2005;162(2):370-76.

5. Fischer PJ, Breakey WR. The epidemiology of alcohol, drug, and mental 
disorders among homeless persons. Am Psychol. 1991;46:1115-28.

6. Nieto G, Gittelman M, Abad A. Homeless Mentally Ill Persons: A bibliography [6] review. International Journal of Psychosocial Rehabilitation. 2008;12:1421.

7. Tripathi A, Nischal A, Dalal PK, Agarwal $\mathrm{V}$, Agarwal $\mathrm{M}$, Trivedi JK, et al. Sociodemographic and clinical profile of homeless mentally ill inpatients in a north Indian medical university. Asian Journal of Psychiatry. 2013;6(5):404-09.

8. Rane A, Nadkarni A, Waikar S, Borkar H. The mental health act in Goa India: [8] profile outcome and implications. International Psychiatry. 2012;9:98-101.

9. Koegel P, Burna MA, Farr RK. The prevalence of specific psychiatric disorders among homeless individuals in the inner city of Loss Angeles. Arch Gen Psychiatry. 1988;45(12):1085-92. 